\title{
GENITORES E O PROVIMENTO DE VERBA ALIMENTÍCIA PARA FILHOS MENORES: ALÉM DE UMA CONDIÇÃO MORAL, UM DEVER LEGAL.
}

\author{
Gabriella Souza Estrogueia de Oliveira
}

Universidade do Oeste Paulista - UNOESTE, curso de Direito, Presidente Prudente, SP. E-mail: Gab.estrogueia@gmail.com

\section{RESUMO \\ O presente artigo tem como objetivo abordar a obrigação familiar prevista na normal constitucional e também no Código Civil brasileiro no que se dirige ao provimento de alimentos aos filhos menores. No qual determina que "o legado de alimentos abrange o sustento, a cura, o vestuário e a casa, enquanto o legatário viver, além da educação, se ele for menor." Diante disto, será apresentada a intervenção do Estado de forma positiva através de leis, protegendo a boa criação dos filhos menores e impondo que os genitores, após examinados possibilidade de pagamento e necessidade de perceber, tenham por fixado valores a serem dirigidos mensalmente aos seus. \\ Palavras-chave: Obrigação familiar, verba alimentícia, condição moral, dever legal. \\ GENITORS AND THE PROVIDE OF VALUE FOOD FOR MINOR CHILDREN: BEYOND A CHARACTER CONDITION, A LAW DUTY.}

\section{ABSTRACT}

The purpose of this article is to address the family obligation foreseen in the normal constitutional and also in the Brazilian Civil Code to which it is directed to the provision of food to the minor children. In which he states that "The legacy of food covers sustenance, healing, clothing and the home, as long as the legatee lives, in addition to education, if he is a minor." Laws, protecting the good creation of the minor children and imposing that the parents, after examined possibility of payment and need to perceive, have for fixed value to be addressed monthly to their own.

Keywords: Family obligation, food allowance, moral condition, legal duty.

\section{INTRODUÇÃO}

Diversas são as exigências financeiras encontradas para atender as necessidades de uma criança. Além de se tratar de direito a uma vida digna, a sociedade possui como regra de moralidade que os pais devem sustentar, criar e educar seus filhos.

Esta obrigação dos genitores em prover alimentos aos seus, justifica-se na atitude moralmente correta. Porém, a moralidade não impõe condutas ao individuo, uma vez que o conceito do que é ético e moralmente correto varia de pessoa para pessoa conforme sua cultura, localização, entre outros aspectos.

Por tal motivo, depara-se com a necessidade de que o Estado intervenha de forma positiva diante da família, visando que sejam os pais obrigados aos olhos da Lei, prestar verba suficiente para a boa e digna criação dos seus, nos quais não residem sob o mesmo imóvel e dependência.

Importante ressaltar, que em se tratando da irrenunciabilidade do poder familiar e o direito indisponível do menor em perceber alimentos, tem-se que, além de toda condição moral e social a justificar essa responsabilidade dos genitores, por força de previsão no texto constitucional e também do Código Civil Brasileiro/2002, esta relação passa a ser assegurada e normatizada pelo ordenamento jurídico brasileiro. 
Uma vez sendo a família a base da sociedade, incumbe-se aos pais papel fundamental na boa construção dos seus, compreendidos como os primeiros educadores e transmissores de princípios e valores com responsabilidade direta na esfera educacional, material, espiritual e psicológica a qualquer indivíduo.

Ante a todas essas premissas, será desenvolvida a apresentação do que rege a Constituição da República Federativa do Brasil e o Código Civil vigente, em proteção aos amparos financeiros indispensáveis ao menor. Devendo estes, serem providos, especialmente, por seus genitores.

\section{METODOLOGIA}

A presente pesquisa utilizou-se de estudo bibliográfico sobre o tema, onde foram utilizados livros de doutrinas, revistas do direito, bem como artigos científicos, e de modo especial os artigos da Constituição Federal/88 e do Código Civil Brasileiro/2002, através do método denominado hipotético-dedutivo.

\section{RESULTADOS}

Incontáveis são os gastos de uma criança ou adolescente nos dias atuais. Isso se dirige a despesas com farmácia, vestuário, calçados, assistência médica, entre tantas outras. Necessidades e despesas que conforme o tempo apenas vem a crescer.

É de cunho social e moral o julgamento de que os pais devem fornecer o necessário para boa criação de seus filhos, a partir de zelo e cuidado. Porém, este julgamento, por não ter força de lei, não direciona condutas obrigatórias ou sancionadas ao indivíduo.

A luz da legislação vigente, a responsabilidade dos pais é dever irrenunciável, ou seja, não se trata de escolha, mas sim de uma obrigação. Tendo em visto as fragilidades de um menor, busca o Estado proteger o desenvolvimento gradativo deste individuo de maneira que relute eficácia e proteção, abarcando o ordenamento jurídico brasileiro deveres aos genitores em virtude ao exercício do poder familiar.

Neste sentido, a Constituição Federal/88, em seu artigo 227 preconiza:

Art. 227. É dever da família, da sociedade e do Estado assegurar à criança, ao adolescente e ao jovem, com absoluta prioridade, o direito à vida, à saúde, à alimentação, à educação, ao lazer, à profissionalização, à cultura, à dignidade, ao respeito, à liberdade e à convivência familiar e comunitária, além de colocá-los a salvo de toda forma de negligência, discriminação, exploração, violência, crueldade e opressão.

O dispositivo alhures, atribui à família deveres em face do menor a fim de que a ele seja proporcionado um desenvolvimento saudável primando o seu melhor interesse e também, tendo por objetivo proteger as garantias individuais de dignidade, respeito, igualdade, entre outras.

Em conseguinte, o artigo 229 da carta constitucional, também atribui aos pais o dever de assistir, criar e educar os filhos, que prevê "os pais têm o dever de assistir, criar e educar os filhos menores, e os filhos maiores têm o dever de ajudar e amparar os pais na velhice, carência ou enfermidade".

Ademais, o referido diploma trata do princípio da paternidade responsável (incluída, por óbvio, a maternidade responsável) e o princípio da dignidade da pessoa humana, como base para o planejamento familiar (artigo 226, §7으 CF/88). A observância destes princípios não é, pois, uma opção. O que dá concretude a esta interpretação.

Em complemento, mas não se tratando do objeto principal analisado neste trabalho, a Lei 8.069/90, Estatuto da Criança e do adolescente (ECA), também apresenta deveres ao poder 
familiar, dirigindo aos pais a obrigação ode zelar pela qualidade material, afetiva, moral e até psicológica do filho menor.

Ensejando base ao raciocínio apresentado, o artigo 3 também do E.C.A. ressalta que toda criança e adolescente goza dos direitos fundamentais dispensados a pessoa humana, em comparativo ao artigo 5 o da Carta Maior, tendo salvo sua vida, sua liberdade, sua igualdade, sua dignidade, entre tantos outros.

É o que também conclui Taísa Maria Macena Lima (1984, p. 31), apresentando em sua obra que o dever de criação também se referente ao dever de atendimento das mais diversas necessidades do menor, partindo das demandas básicas até as mais complexas.

No mesmo ponto, ensina Yussef Said Cahali, em seu livro Dos Alimentos (4. ed. São Paulo: RT, p. 15), que:

"O ser humano, por natureza, é carente desde a sua concepção; como tal, segue o seu fadário até o momento que lhe foi reservado como derradeiro; nessa dilação temporal - mais ou menos prolongada -, a sua dependência dos alimentos é uma constante, posta como condição devida. Daí a expressividade da palavra 'alimentos' no seu significado vulgar: tudo aquilo que é necessário à conservação do ser humano com vida..."

Também como estudo principal deste trabalho, à luz do Código Civil Brasileiro, tem-se o artigo 1.920, conceituando alimentos como "o legado de alimentos abrange o sustento, a cura, o vestuário e a casa, enquanto o legatário viver, além da educação, se ele for menor".

Por tudo isto, conclui que a prestação de alimentos não se refere apenas ao termo alimentício, no tocante sentido óbvio da palavra. Mas sim, quando se tratar de prestação de alimentos, abrange-se aos suprimentos das necessidades também de vestuário, calçados entre todos os outros aspectos necessários para a boa criação de uma criança.

Diante da extrema necessidade, não poderia o Estado deixar a mercê a boa ou não vontade dos genitores em prover tais recursos aos seus filhos menores, sendo necessário que a primazia legal fixa-se claramente o dever e a necessidades desses indivíduos.

O respeitado doutrinador civilista Carlos Roberto Gonçalves em sua obra Direito Civil Brasileiro - Direito de Família - volume 5, fortalece e amplia conceitualmente ao tema outros valores, discorrendo com precisão que:

Entende-se por alimentos as prestações periódicas fornecidas por alguém para suprir as necessidades de outrem e assim assegurar a sua subsistência como uma modalidade de assistência imposta por lei, de ministrar os recursos necessários à subsistência, à conservação da vida, tanto física como moral e social do indivíduo, sendo, portanto, a obrigação alimentar.

De tal modo, muito além de todo conhecimento e justificativa social e moral no qual os pais devem fornecer a base necessária aos seus, de modo especial, a base financeira, uma vez que a legislação preconiza expressamente tal obrigação e tal direito dos filhos menores, é verificada a existência de um instrumento de intervenção positiva do Estado.

Apenas para complemento e curiosidade, conforme previsto no Código Civil, art. 1.696 "O direito à prestação de alimentos é recíproco entre pais e filhos, e extensivo a todos os ascendentes, recaindo a obrigação nos mais próximos em grau, uns em falta de outros". Ou seja, aplicando a este estudo, tem-se também a possibilidade que diante da proteção da vida do menor, é autorizado que em casos do provedor da verba não possuir qualquer meio de provê-la, esta obrigação será estendida aos mais próximos em grau, como por exemplo, aos avós. 


\section{DISCUSSÃO}

O conhecimento de cunho social e moral, remete os genitores como responsáveis dos filhos que geraram, sejam em assistência sentimental, espiritual, financeira, entre outras, até que este tenha a capacidade e acesso aos meios necessários de prover seu próprio sustento.

Porém, em se tratando de circunstâncias que atingem diretamente a vida, bem jurídico protegido, surgem dúvidas quanto ao posicionamento do próprio poder do Estado na classificação dessa obrigação materna, paterna e em exceção, de outras figuras familiares, a ponto que atenda a tais carências.

Visto isto, esta obrigação moral dos pais, torna-se um dever legal imposto pela Carta Magna e pelo Código Civil/2002, trazendo a esta relação pai-filho, segurança jurídica e social de maneira eficaz.

\section{CONCLUSÃO}

Por todo estudo realizado, é possível concluir que o julgamento moral não é o suficiente para arbitrar e assegurar o essencial a sociedade.

Um desses diversos pontos é a obrigação dos genitores em prover alimentos aos seus filhos menores, no qual não se trata apenas de condição, mas sim, de dever amparado em lei.

A justificativa é que o Estado possui o dever de intervir positivamente nas relações, tendo como base os objetivos da republica e a busca do bem comum. Diferente não seria no âmbito familiar, no qual se omitindo, deixaria mercê às necessidades do indivíduo menor.

Logo, a CRFB e o Código Civil Brasileiro, preveem expressamente a obrigação dos genitores no sustento dos seus.

Afinal, enquanto não houver responsabilidade pelos seres concebidos e trazidos à luz independentemente da discussão sobre modelos familiares - a violência, a intolerância, a miséria e o egoísmo dominarão todas as demais relações sociais, minando as esperanças de uma sociedade livre, justa e solidária, cuja construção é um dos objetivos fundamentais da própria Pátria.

\section{REFERÊNCIAS}

BRASIL. Constituição (1998). Constituição da República Federativa do Brasil. Brasília: Senado Federal, 2011. Promulgada em 5 de outubro de 1988. Disponível em: <http://www.planalto.gov.br/ccivil_03/constituicao/constituicaocompilado.htm> Acesso em 08 de agosto de 2017.

CAHALI, Yussef Said, 1930. Dos Alimentos. 4ạ Edição. São Paulo. Revista dos Tribunais.

DILL, Michele Amaral. CALDERAN, T. S. Os deveres intrínsecos ao poder familiar e a responsabilidade dos pais pelo descumprimento. Disponível em: <http://www.ambitojuridico.com.br/site/index.php?n_link=revista_artigos_leitura\&artigo_id=831 5> Acesso em 13 de setembro de 2017.

DINIZ, Maria Helena. Código Civil Anotado. 17ạ Edição, Saraiva 2014.

DINIZ, Maria Helena de. Curso de Direito Civil Brasileiro: Direito de Família. 22. ed. rev. Atual. São Paulo: Saraiva. 2007. v.5. 
Estatuto da Criança e do Adolescente Comentado Disponível em: <https://www.direitocom.com/estatuto-da-crianca-e-adolescente-comentado> Acesso em 09 de agosto de 2017.

GONÇALVES, Carlos Roberto. Direito Civil Brasileiro - Direito de Família - 14ạ Edição. Saraiva. 2017. V.6

LEI No 8.069, DE 13 DE JULHO DE 1990. Disponível em: <http://www.planalto.gov.br/ccivil_03/leis/L8069.htm>_Acesso em 10 de agosto de 2017.

LIMA, Taísa Maria Macena. Guarda e afeto: tipo sociológico em busca de um tipo jurídico. Controvérsias no sistema de filiação. Belo Horizonte: Universidade Federal de Minas Gerais, 1984. p. 31.

PAULO, Vicente. Alexandrino, Marcelo. Direito Constitucional descomplicado. 7 ed. Rio de Janeiro: Forense; São Paulo: Método, 2011. 